\title{
Web Platform to Create Memory Games for Educational Purposes
}

\author{
Luz de Estrella Hernández-Rivera, Carlos R. Jaimez-González*, Betzabet García-Mendoza
}

\author{
Departamento de Tecnologías de la Información, Universidad Autónoma Metropolitana, \\ Unidad Cuajimalpa, Ciudad de México, México
}

Received August 8, 2020; Revised October 7, 2020; Accepted October 19, 2020

\begin{abstract}
Cite This Paper in the following Citation Styles
(a): [1] Luz de Estrella Hernández-Rivera, Carlos R. Jaimez-González, Betzabet Garcia-Mendoza, "Web Platform to Create Memory Games for Educational Purposes," Universal Journal of Educational Research, Vol. 8, No. 12, pp. 6498-6508, 2020. DOI: 10.13189/ujer.2020.081215.
\end{abstract}

(b): Luz de Estrella Hernández-Rivera, Carlos R. Jaimez-González, Betzabet García-Mendoza (2020). Web Platform to Create Memory Games for Educational Purposes. Universal Journal of Educational Research, 8(12), 6498-6508. DOI: 10.13189/ujer.2020.081215.

Copyright $\bigcirc 2020$ by authors, all rights reserved. Authors agree that this article remains permanently open access under the terms of the Creative Commons Attribution License 4.0 International License

\begin{abstract}
Games are considered entertaining activities that help the mental and physical stimulation of people; they are especially useful and necessary for learning and cognitive development in children. On the other hand, human's memory has an important role in playing games because of the concentration and memorization processes that are carried out. The memory game in particular serves as a complement in the cognitive development of the human being; it consists of finding equal pairs of cards in a diverse set of them. This paper presents a web platform to create memory games for educational purposes, intended to support the teaching-learning process of different subjects for primary school children. The platform is divided into two systems: the administrator system, which is used by teachers in order to create memory games; and the games themselves, which are generated by the platform for the students to play. The modules that compose the web platform are described and some of the interfaces of the system are shown. A comparative analysis of five existing tools for memory games is also presented, in which the most relevant features were reviewed, such as the possibility to generate new games, the cost to play games, the option to create different types of memory games, the possibility to store the games in the system, the interactivity of the interface, among others.
\end{abstract}

Keywords Memory Games, Primary School Children, Educational Technology, Ludic Games, Teaching-Learning Process, Web Platform

\section{Introduction}

Formal education is an important complement in life, because it allows going through different stages of training. From a young age, a person's academic life begins by going to educational institutes where they acquire different knowledge. School is mainly a teaching center that trains each individual intellectually, but also allows social coexistence between people. Something that is also very important to mention is that formal education has gradually shown changes and innovations in its teaching methods to guarantee a better quality in education. The incorporation of Information and Communication Technologies (ICT) was one of the aspects integrated to these changes; the inclusion of digital tools such as translators, educational games, teaching platforms, among others, which have helped in the teaching-learning process producing very favorable results for students and teachers [1].

New teaching-learning methodologies have facilitated the development of skills in students. It is now more feasible to learn by playing with educational tools than to continue concentrating on the traditional school, which focused more on the teacher and not on the students. At the end of the 19th century and the beginning of the 20th, recognized educators analyzed the rigorous form of teaching and learning, concluding that education should change to put more attention on the student [2].

Concerning the tools that students access, they only acquire pedagogical value when they are interpreted as intermediaries between the student and the teacher or 
between peers, in order to facilitate the interactive processes of knowledge generation [1].

Educational platforms have had a great impact on people's learning, thanks to the incorporation of ICT, which have been integrated into new educational models that consider recreational tools with educational approaches. These tools have helped children and adults to continue developing cognitive abilities in a much simpler way [3].

The web platform presented in this paper will serve as a complementary tool that helps in the teaching-learning process. It consists of a generator of different types of memory games that mainly supports primary school children to complement their learning of different topics.

The rest of the paper is organized as follows. Section 2 presents the theoretical framework, where there is a discussion of some important aspects, such as the game as a ludic activity, the ICT-mediated learning, the memory and memory games considered as ludic tools. Section 3 presents an analysis and comparison of some relevant features of existing similar tools for playing memory games. Section 4 describes the proposed web platform to create memory games, along with its modules and some preliminary interfaces. Finally, conclusions and future work are presented in section 5 .

\section{Theoretical Framework}

Ludic games as part of the teaching-learning process have been investigated and analyzed by important fields of study such as psychology, pedagogy, computer science, among others, which have provided different mechanisms for the cognitive process. The following subsections describe some important aspects and concepts involved in the work presented in this paper.

\subsection{The Game as a Ludic Activity}

The game is considered one of the most entertaining activities that help the mental and physical stimulation of people. From birth, games are useful and necessary for learning and cognitive development in children. According to studies, children who lack the use of games, lose the most important learning tool that they have at that stage of life, because thanks to them, children develop mental functions such as attention, perception, memory, thought, imagination, judgment, logical reasoning and language [4]. This set of acquired skills are favorable in the educational system, since it makes the children's way of learning easier; helping them to get more quickly all the knowledge that the teacher gives them. At this point, it is where ludic activities with pedagogical approaches are introduced, which serve as complement in the teaching-learning process.

Studies carried out by psychologists and educators provide the following criteria about the games. Brower states that games are essential for every developing child
[3]. According to Zapata, games are fundamental elements in the school environment, concluding that children learn more while playing, so this form of teaching should become the main focus [3]. On the other hand, Vigotsky affirms that the imagination is born in the game and before the game there is no imagination, therefore, the game is a driving force for the child's mental development [4].

For these reasons, ludic games have been incorporated into the new forms of teaching-learning processes. Supporting the previous affirmations, in [5] it is sustained that ludic games allow motivating and improving the tasks carried out in the classroom. In addition, a study is cited, in which games can be used in the teaching-learning process to meet the objectives of the class and demonstrate that activities improve student performance. A study carried out in [6] exposes that different disciplines such as psychology and pedagogy relate that the student and learning are connected through didactic activities, which are increasingly updated in parallel with science and technology.

\subsection{ICT-mediated Learning}

ICT have progressively transformed the way of life of human beings. Throughout these changes, various aspects have been favored, such as the way of accessing knowledge and interacting with society. From the educational approach, communication is a main element in the teaching-learning process, since it has offered innovative supports that facilitate access to education in person or at distance [1].

ICT have not only changed access to education, but have also provided new forms of teaching such as learning styles, focused mainly on students, allowing the traditional school to be left behind. Learning styles are defined as cognitive, affective and physiological aspects, which serve as performance indicators to know how students perceive, interact and respond in a learning environment. The learning environments mediated by ICT are intended to be exploited by students, in such a way that it benefits them in the learning process and supports the teacher in the teaching process, since in an educational system, the teacher has to guide and accompany the student throughout the learning process [7].

\subsection{Memory}

When playing a game, concentration and memorization are carried out in a conscious and funny way, and without any difficulties. For this purpose, the concept of memory is analyzed in this section. Soledad Ballesteros carried out a study [8], in which it is stated that memory is a psychological process that serves to store information; however, she says that memory may fail circumstantially, momentarily, or permanently. For this reason, psychologists such as Atkinson and Shiffrin [8] proposed 
structural models where they affirm that human memory can be divided into three different structures, mentioned below.

The first structure refers to sensory records, which receive large amounts of information through the senses and store them for a very limited duration. The retention of information in sensory records is approximately a second. The most studied sensory memories to date are iconic and echoic memory. Iconic memory has a large storage capacity where information obtained from the visual medium is stored; the disadvantage is that the information is only saved for a very short time [8]. On the other hand, echoic memory stores information from the auditive system; it also retains superficial aspects, but in an almost unlimited way [8].

The second structure is short-term memory, just as the first structure has limited storage capacity; memories remain approximately from 5 to 15 seconds. The information transfer process is through the sensory record, where all the information stored is transferred to short-term memory, which briefly retains the information before being permanently or almost permanently stored in long-term memory [8].

Finally, the third structure is long-term memory, where information from short-term memory is transferred to long-term memory for permanent storage. Tulving's book Elements of the episodic memory explains the two types of long-term memory: episodic and semantic. Each of them contains different information and constitutes functionally different systems. Personal experiences and memories are stored in episodic memory; while semantic memory refers to knowledge of the world and language [8].

\subsection{The Memory Game as a Ludic Tool}

The memory game is a board and digital game, which serves as a complement in the cognitive development of the human being. The game consists of finding equal pairs of cards in a diverse set of them, with different shapes. When interacting with this type of game, the images are stored by the iconic sensory memory, which retains the information captured for a limited time. The thesis works and publications discussed in this subsection, support that memory games have had an impact on the teaching-learning process, obtaining favorable results.

Pamela Cruz focused her degree project [9] on a digital pedagogical game that helped 4-year-old children in the development of mathematical logic. Through the methods used to collect information, a viable solution to this problem was found, giving rise to the development of a digital memory game. The lack of technological knowledge as a result of the study carried out, forced teachers to be trained in this tool and offer them support techniques so that they could teach children mathematical logic through the digital ludic tool implemented.

On the other hand, the study described in [10], which was published by Liliana Martinea, Elvira Rincón and Ángeles Domínguez, focused on solving first grade equations cooperatively and individually in secondary school children, through dynamic games. From the study carried out, information was obtained that led to the implementation of balance and memory games, which achieved the main objective.

The study presented in [11] empirically investigated how preschool children play memory games in both digital and analogue form and how the artefacts mediate the children's engagement. The findings show that two types of memory games evolved into distinctively different kinds of activities. The results indicated that it is difficult to predict learning outcomes from specific games and there is the need of a discussion on how digital artefacts can mediate activities.

A study described in [12] tested the benefits of tabletbased training games that targeted each of these areas for improving the mathematical knowledge of kindergartenage children. The results suggested that playing a number game improved kindergarten children's numerical knowledge at the latent level, and these improvements remained stable as assessed a month later. The results demonstrate that computerized memory games that target both domain-specific and domain-general skills can benefit a broad range of kindergarten-aged children.

Another study [13] investigated the effects of using scientific educational games in teaching Kingdoms of Living Things on students' academic achievement and retention of knowledge. The study also assessed students' perceptions of these educational games. 68 ninth grade students constituted the study group of this research. The results put forth that educational games enhance students' achievement and are an effective tool in providing the retention of new knowledge. The students found the games informative, entertaining and reinforcing their learning.

Finally, in the article published by Víctor Chi-Pech, Lizzie Narváez and José López, two types of games were developed for elementary school children, with the purpose of helping the teacher and the student to complement the teaching and learning processes. The main game was the memory game, which had two tasks considered; on the one hand, that children from second grade onwards would review the multiplication tables, and on the other hand, that they could learn the names of animals in English. The second game was a map of the Mexican Republic focused on fourth and fifth grade children, which was intended for students to locate the states of the country and their capitals. These two games were tested in different schools in eastern Yucatan, showing very favorable results [14].

\section{Related Work}

There are web tools that have been developed in order to help in the teaching-learning process. In this section five 
different tools are analyzed, which are memory games created to help in children's mental development. A comparative analysis of the tools is also provided at the end of the section, which is carried out through a table with the most relevant features of each tool. An explanation of each feature is also provided. The tools analyzed are the following: Gynzy [15], Hello Kids [16], Pocoyo [17], ABC tree [18], and Luca Games [19].

\subsection{Gynzy}

Gynzy [15] is an American company, which develops games and educational activities that serve as support for children's learning. This company provides a web tool that covers different school subjects and has different usage options, such as: electronic whiteboard, activity storage and classification of favorite games. This tool is accessible to the user, since it allows using the preloaded educational material or generating new activities.

Memory games are part of the variety of games offered. Students interacting with this platform will improve their observation and memory skills by matching words and pictures from the cards shown on the board. The memory game of words contains a section for the user to enter the words, choose the size of the board (number of cards), and save the words entered in a file.

The memory game of images is limited, because the user can only choose topics included in the tool, the type of image (illustration or photo) and the number of cards. Figure 1 shows a screenshot of the memory game of images. This tool has two different plans: free for 60 days and commercial use, where you can get more benefits, such as an administrator portal and collaboration with other users.

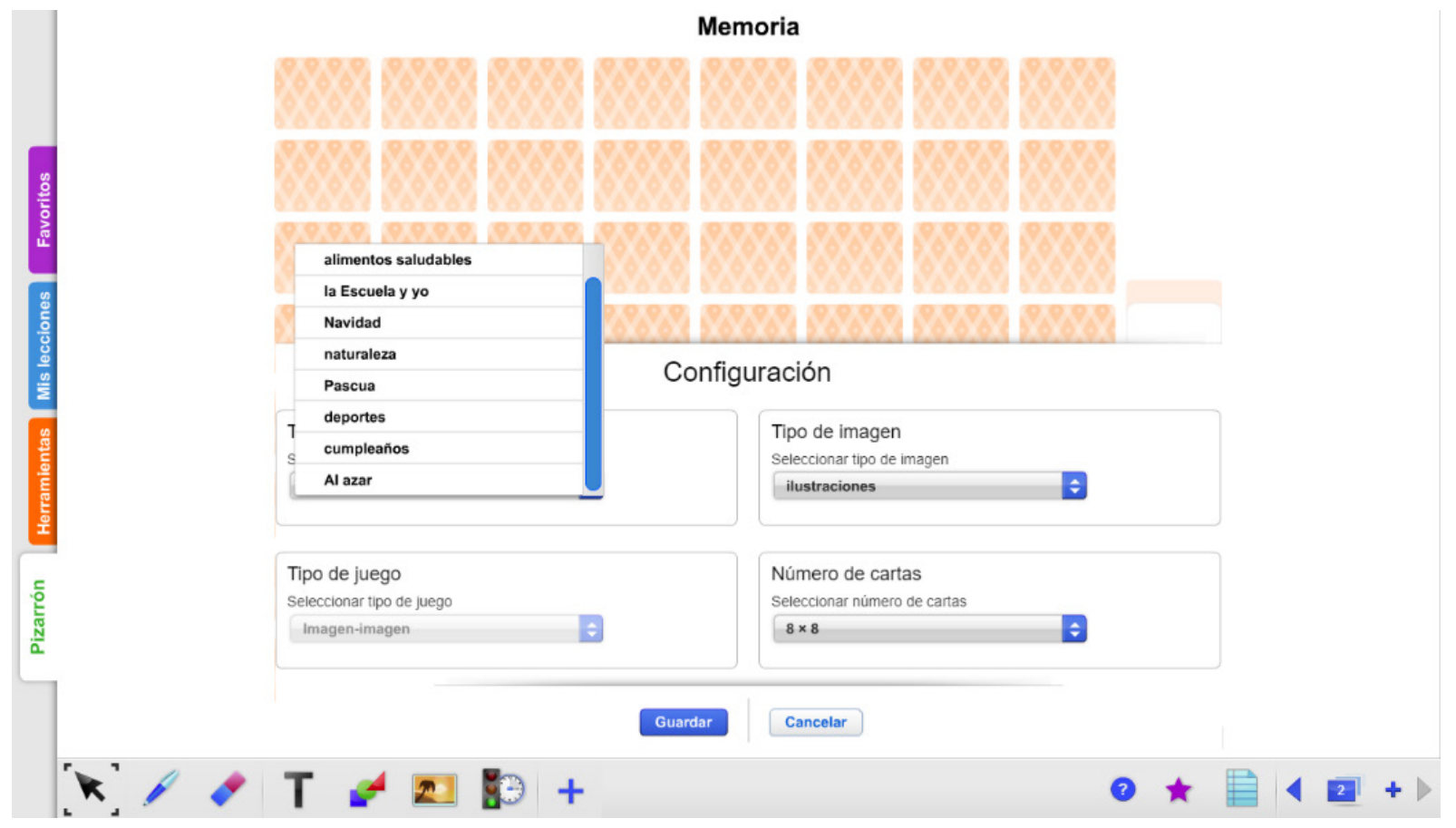

Figure 1. Content settings in Gynzy 


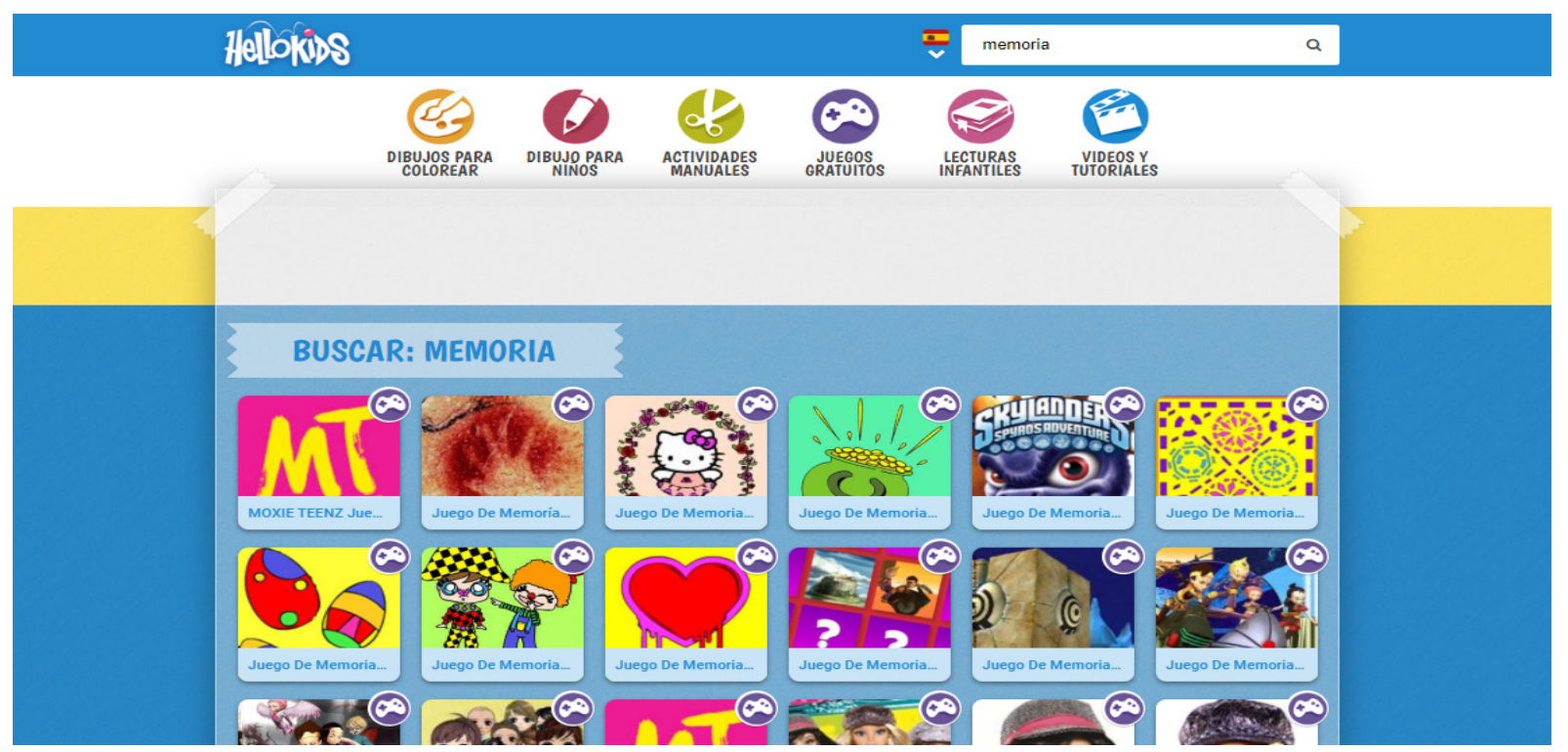

Figure 2. Different memory games in Hello Kids

\section{Juegos de memoria y retentiva}

\section{Entrenad vuestra mente con ejercicios de memoria de Pocoyo}

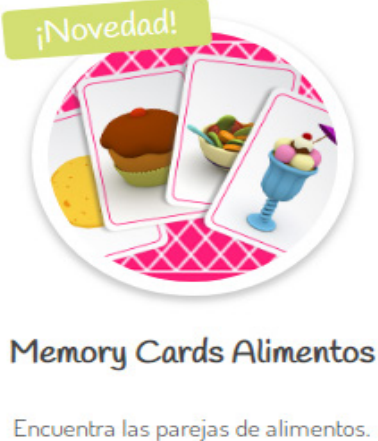

Encuentra las parejas de alimentos.

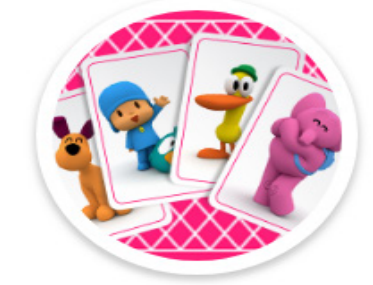

Memory Cards Personajes

Encuentra las parejas de cartas de los personajes de Pocoyo.

Jugar ahora Compartir

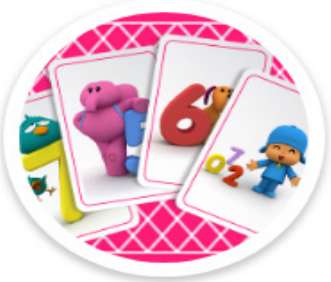

Memory Cards Números

Encuentra las parejas de cartas de números.

Jugar ahora Compartir

Figure 3. Different topics of memory games in Pocoyo

\subsection{Hello Kids}

Hello Kids [16] is a website that contains various activities for children's mental development such as online and printable drawings, drawing tutorials, crafts, videos, games, songs and stories. The website includes memory games, where there are various topics to choose from. Figure 2 shows a screenshot with different memory games, in which the user can choose a level of difficulty (very easy, easy and normal), depending on the child's abilities or their age. When a child completes a level, the points obtained allow continuing with the next level of difficulty or choosing a different game. It should be noted that this website does not allow creating new memory games.

\subsection{Pocoyo}

Pocoyo [17] is a free platform for mobile and desktop devices, and it has a wide variety of educational and didactic games aimed at stimulating the creativity and imagination of children. Although they are interactive games, it allows the child to develop their interest and learn to use new technologies. Figure 3 shows a screenshot of the tool with the eight different topics of memory games. In each game the degree of difficulty is increased if the pairs of cards are completed in the established time. It is also possible to view the number of attempts and the total score that was obtained in the levels accomplished. The platform does not have the option to generate new memory games; the user can only play with the existing games.

\subsection{ABC Tree}

$\mathrm{ABC}$ tree [18] is a website that has different types of games and educational activities for different areas such as 
Spanish, mathematics, natural sciences, English, biology, drawing, among others. The website includes a variety of memory games to reinforce child's skills or generate new knowledge. Similar to the previous tools, ABC tree does not have the option to create new memory games. An example of a memory game is shown in Figure 4, in which the board is composed of 12 cards.

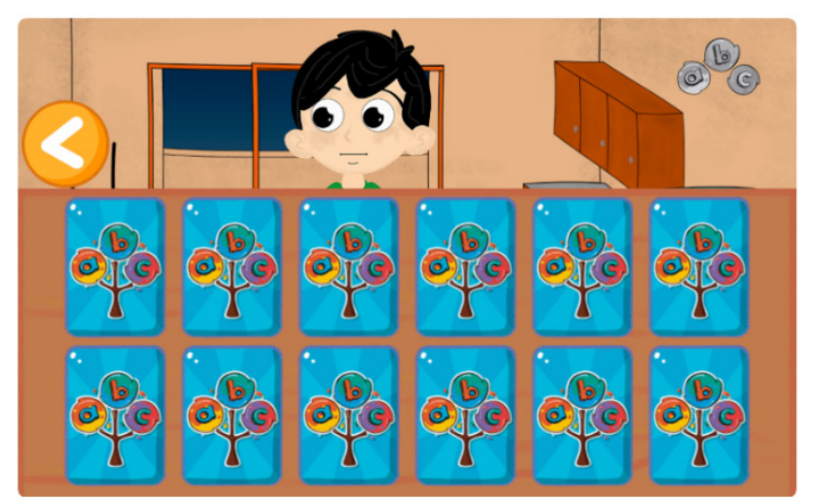

Figure 4. Memory game in $\mathrm{ABC}$ tree

\subsection{Luca Games}

Luca Games [19] is a free educational platform where it is possible to play as a guest or registered user. The tool has games from different learning areas; the games are organized by categories and levels of difficulty. Luca Games does not allow the user to create new memory games. Each game has seven stages and they are developed in such a way that each time it is played the stages are different; this way the game will never be repeated and the students can play it as many times as required. Finally, in each stage the user can see the time it takes to complete it, as illustrated at the bottom of Figure 5, where the board is composed of 12 cards.

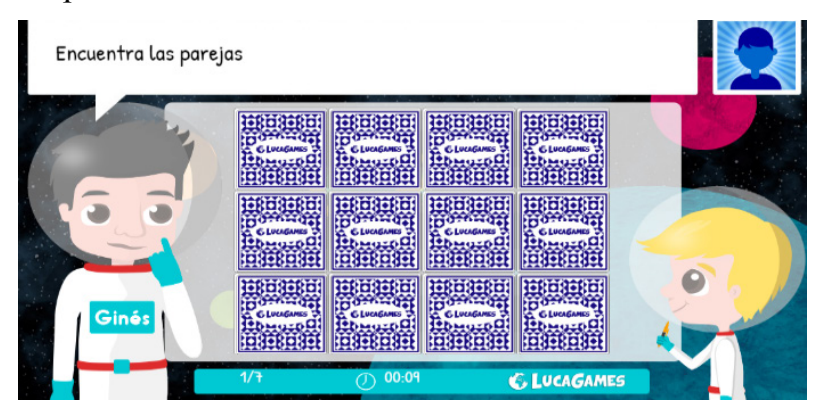

Figure 5. Memory game with different stages in Luca Games

\subsection{Comparison Table}

This section provides an explanation of important features found after analyzing the previously presented tools, with the aim of taking them into consideration for the proposed web platform. It is worth mentioning that other tools were also reviewed such as: Children's games [20], Pictogames [21], Memo-games [22], Free memory games [23] and Children's games pum [24]; which were not considered in the comparison because they were not as relevant as the others.

Table 1 shows a comparison of the features analyzed. The tools shown in Table 1 are the following: T1) Gynzy; T2) Hello Kids; T3) Pocoyo; T4) ABC tree; T5) Luca Games; and T6) the proposed web platform. The tick indicates that the tool has the feature, while the cross indicates that the tool does not have it.

Table 1. Features of the analyzed tools

\begin{tabular}{|c|c|c|c|c|c|c|}
\hline Features & T1 & T2 & T3 & T4 & T5 & T6 \\
\hline Web application & $\checkmark$ & $\checkmark$ & $\checkmark$ & $\checkmark$ & $\checkmark$ & $\checkmark$ \\
\hline Free platform & x & $\checkmark$ & $\checkmark$ & $\checkmark$ & $\checkmark$ & $\checkmark$ \\
\hline Game generator & $\checkmark$ & x & x & x & x & $\checkmark$ \\
\hline Words and images & $\checkmark$ & x & x & x & x & $\checkmark$ \\
\hline Storage of games & $\checkmark$ & x & x & x & x & $\checkmark$ \\
\hline Difficulty and cards & $\checkmark$ & $\checkmark$ & x & $\checkmark$ & $\checkmark$ & $\checkmark$ \\
\hline Interactive interface & x & x & $\checkmark$ & $\checkmark$ & $\checkmark$ & $\checkmark$ \\
\hline Timer or stopwatch & $\mathbf{x}$ & $\mathbf{x}$ & $\checkmark$ & $\mathbf{x}$ & $\checkmark$ & $\checkmark$ \\
\hline Reset the game & $\checkmark$ & $\mathbf{x}$ & $\mathbf{x}$ & $\mathbf{x}$ & $\mathbf{x}$ & $\checkmark$ \\
\hline Number of attempts & $\mathbf{x}$ & $\mathbf{x}$ & $\checkmark$ & $\mathbf{x}$ & $\mathbf{x}$ & $\checkmark$ \\
\hline Display score & $\mathbf{x}$ & $\checkmark$ & $\checkmark$ & $\mathbf{x}$ & $\checkmark$ & $\checkmark$ \\
\hline Stages or sublevels & $\mathbf{x}$ & $\mathbf{x}$ & $\mathbf{x}$ & $\checkmark$ & $\checkmark$ & $\checkmark$ \\
\hline Sound & $\mathbf{x}$ & $\mathbf{x}$ & $\checkmark$ & $\checkmark$ & $\checkmark$ & $\checkmark$ \\
\hline Turn & $\checkmark$ & $\mathbf{x}$ & $\mathbf{x}$ & $\mathbf{x}$ & $\mathbf{x}$ & $\checkmark$ \\
\hline
\end{tabular}

Web application. This feature indicates that the tool has been developed as a web application and is used through a web browser with Internet access.

Free platform. It indicates that the user can interact at no cost with the tool, it is free.

Game generator. This feature indicates that the tool has an administrator system, which is capable of generating new memory games with the number of cards specified, the time and the words or images that the user provides.

Words and images. It indicates that the tool allows the user to add words or images to be used as cards. This refers to the possibility of having different types of games.

Storage of games. This feature indicates that the tool has an option that allows saving the games generated.

Difficulty and cards. It indicates that the memory game allows the user to choose the degree of difficulty or the number of cards to be used in a game.

Interactive interface. This feature indicates that the game interface is interactive with the user.

Timer or stopwatch. It indicates that the tool has a stopwatch to count the time to complete each game.

Reset the game. This feature indicates that the tool has an option that allows the user to reset the cards of the game (restart the game).

Number of attempts. It indicates that the tool counts and displays the number of times that an unsuccessful attempt has been made to find a pair of cards.

Display score. This feature indicates that the tool keeps track of the score that a user obtains at the end of a game. 
Stages or sublevels. It indicates that the tool has different stages or sublevels for the memory games.

Sound. This feature indicates that the memory game can pronounce the name of the card or make a sound when clicking on any card.

Turn. It indicates that the tool shows the active user in a memory game.

\section{Proposed Web Platform}

After analyzing the different tools and comparing them, the proposed web platform will have all the features presented in the previous section. The proposed platform is divided into two systems: the administrator system, which will be used by teachers in order to create new memory games; and the games themselves, which are generated by the platform for the students to play. This section describes the modules that compose the web platform to carry out its functionality, and the preliminary interfaces are shown.

\subsection{Modules}

Module of configuration for the classic memory game. This module serves to configure all the information involved when creating a classic memory game, such as the size of the board, the images to be used, among other configuration options.

Module of configuration for the words memory game. This module allows configuring all the information involved when creating a words memory game, such as the size of the board, the words to be used, among other configuration options.

Module of configuration for the word-image memory game. This module is in charge of the configuration of all the information involved when creating a word-image memory game, such as the size of the board, the words and images to be used, among other configuration options.

Module of configuration for the images memory game.

This module is in charge of the configuration of all the information involved when creating an images memory game, such as the size of the board, the different images related to be used, among other configuration options.

Module of storage of games. This module allows storing, modifying and deleting games with all their relevant information. This module has communication with the other modules that configure each type of memory game.

Module of progress statistics. This module allows to keep track of the information for the score and attempts carried out by the user in each game.

Module of visualization of games. This module is in charge of displaying the different types of memory games (classic, words, word-image, images) that the administrator created. It also allows the user to interact with each game.

\subsection{Interface Prototypes}

The preliminary interfaces of the web platform have been developed, along with some of their functionality. Figure 6 shows the administrator system, with the interface to choose the type of memory game to be created. There are four types of memory games as it is illustrated in Figure 6: classic memory game, where a pair of cards is composed by two equal images; word-image memory game, where a pair of cards is composed by one word and one image, defined by the teacher; words memory game, where a pair of cards is composed by two words defined by the teacher; and images memory game, where a pair of cards is composed by two different images defined by the teacher.

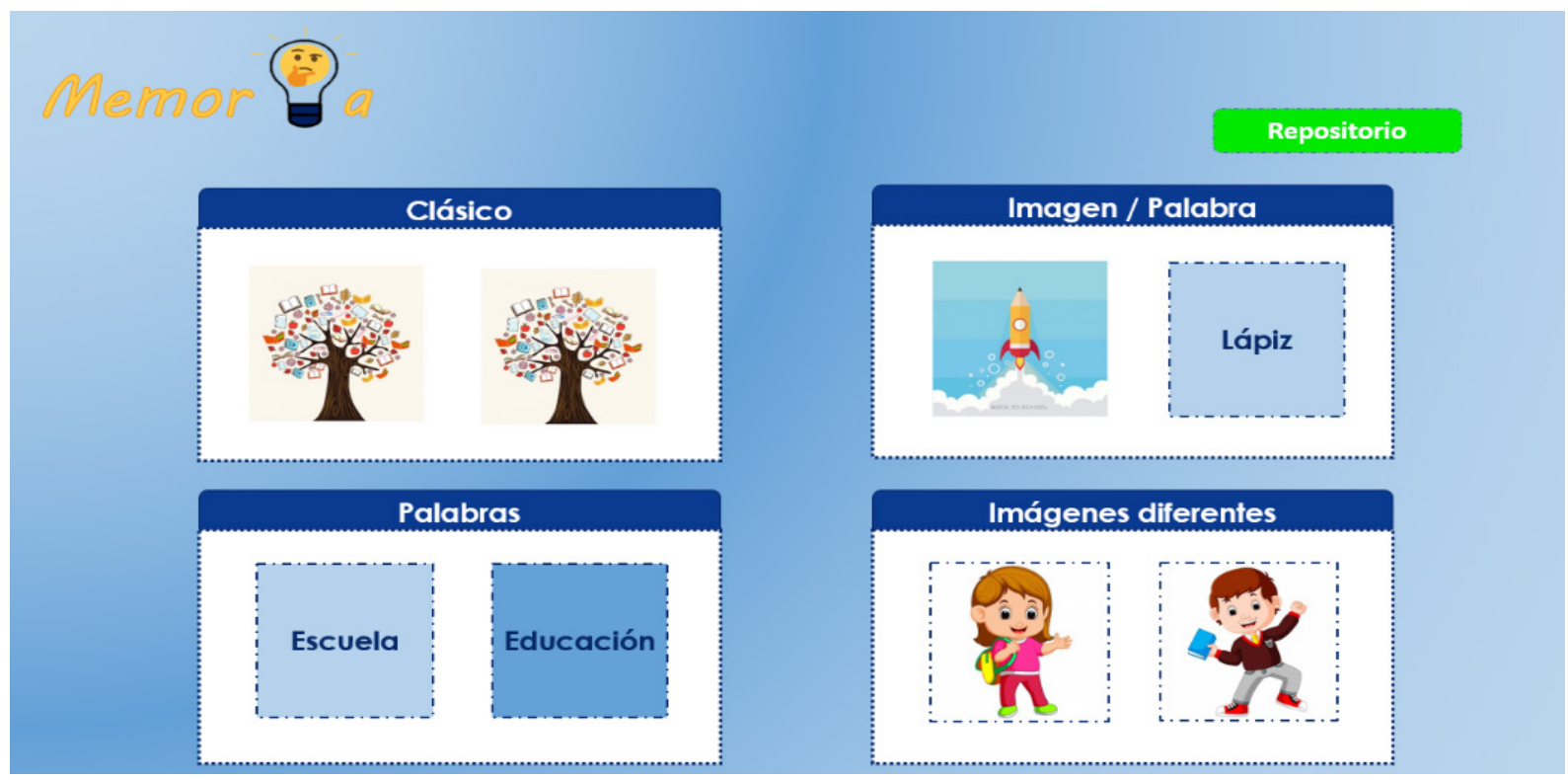

Figure 6. Interface with the types of memory games 


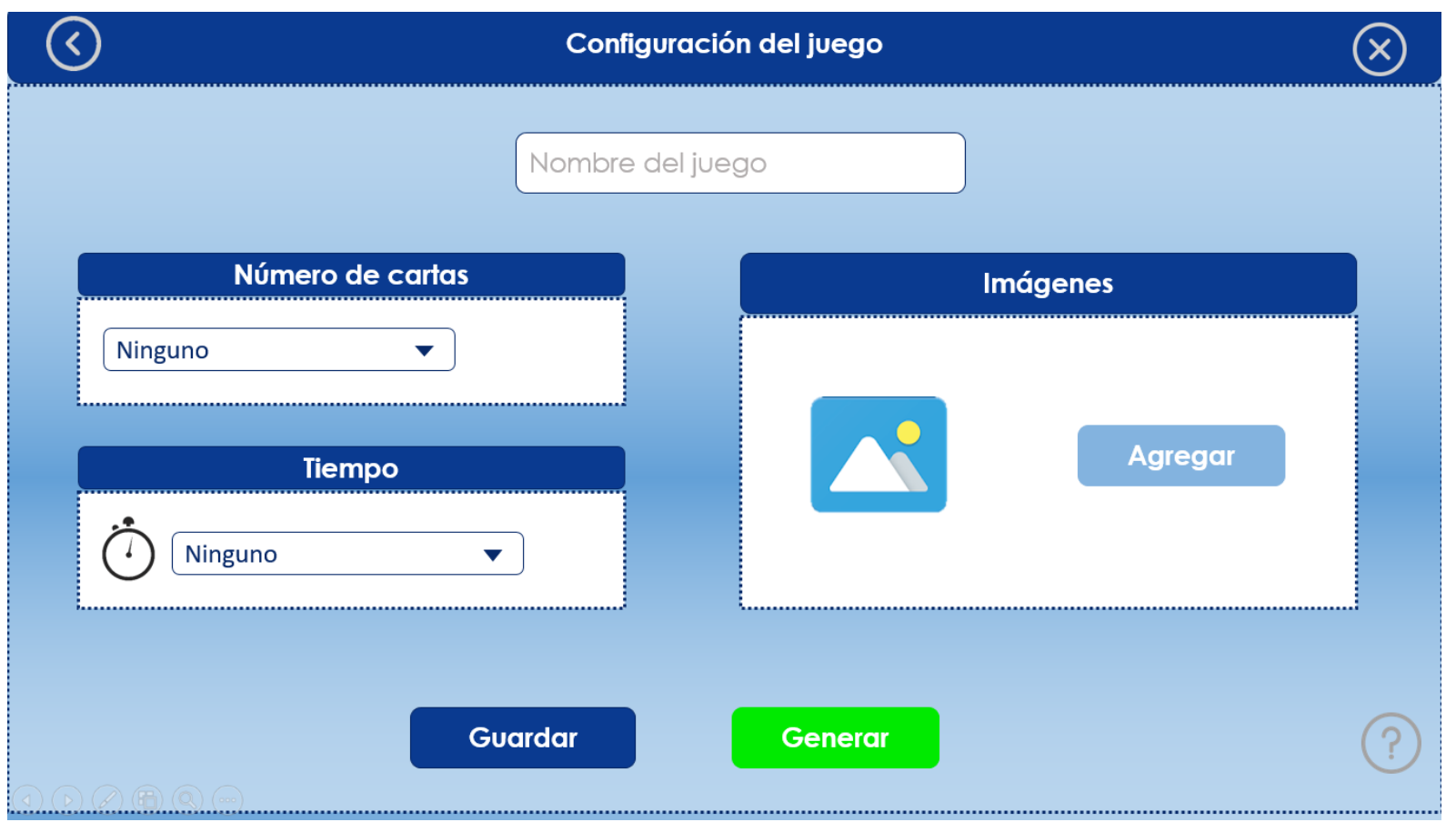

Figure 7. Interface for the configuration of a memory game

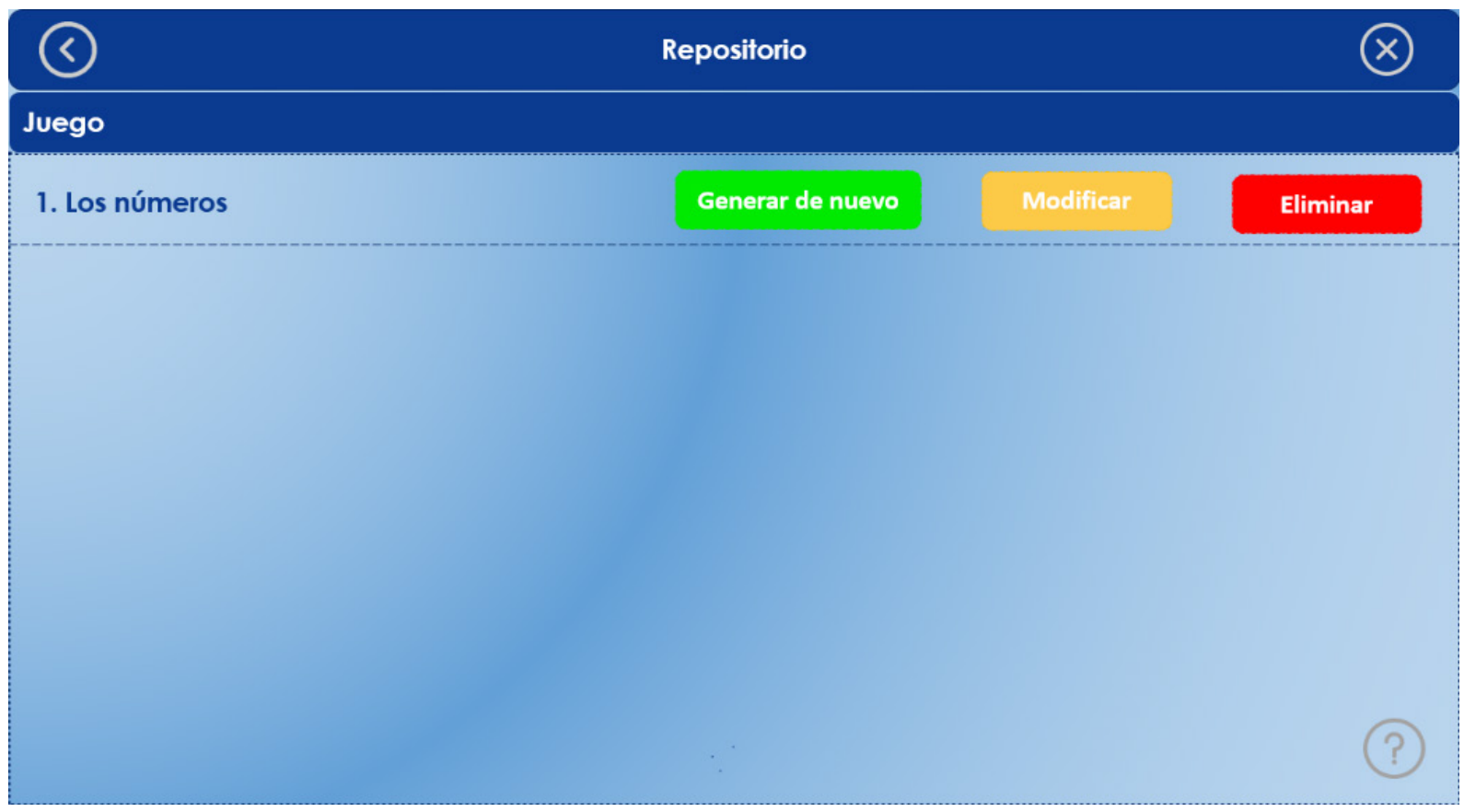

Figure 8. Interface for the repository of memory games created

Once the teacher has chosen the type of memory game to be created, the configuration of the game takes place, as it is illustrated in Figure 7, where a classic game has been selected. It is necessary to provide the name of the game to be created, the size of the board, the time established to be completed, and the images for the cards.

Figure 8 displays the interface for the repository of the web platform where the teacher can visualize all the games created; in this case only one game is listed. There are three options available: generating a new game, modifying an existing game, and deleting an existing game.

The game previously generated is shown in Figure 9, where the name of the game is on the top, the number of attempts is on the left side, the points accumulated is on the right side, the stopwatch is at the center, and the cards are on the center. In this case, Figure 9 represents a classic memory game with a board of 12 cards with 6 pairs in total. There is also a button to restart the game. 


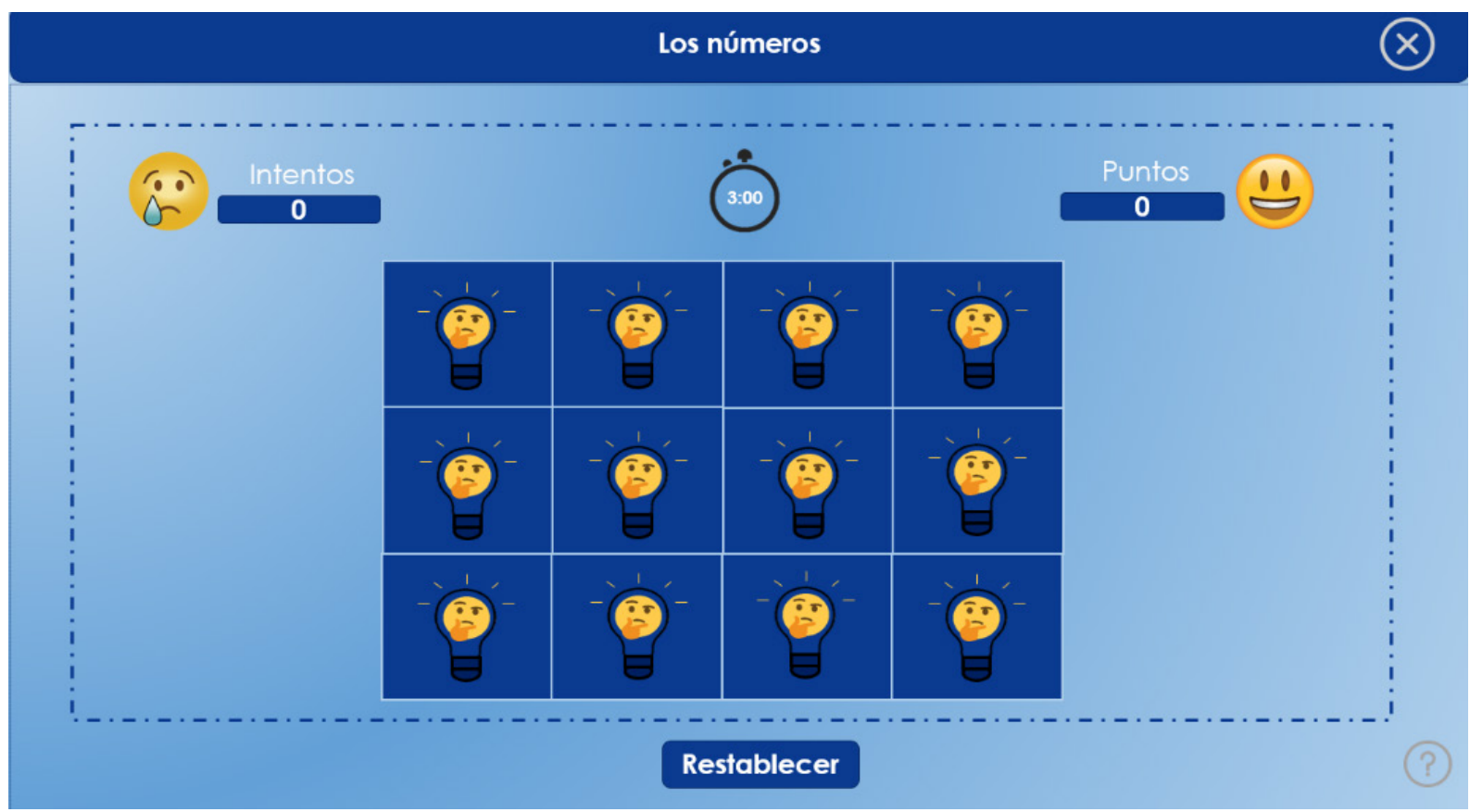

Figure 9. Interface for a classic memory game created

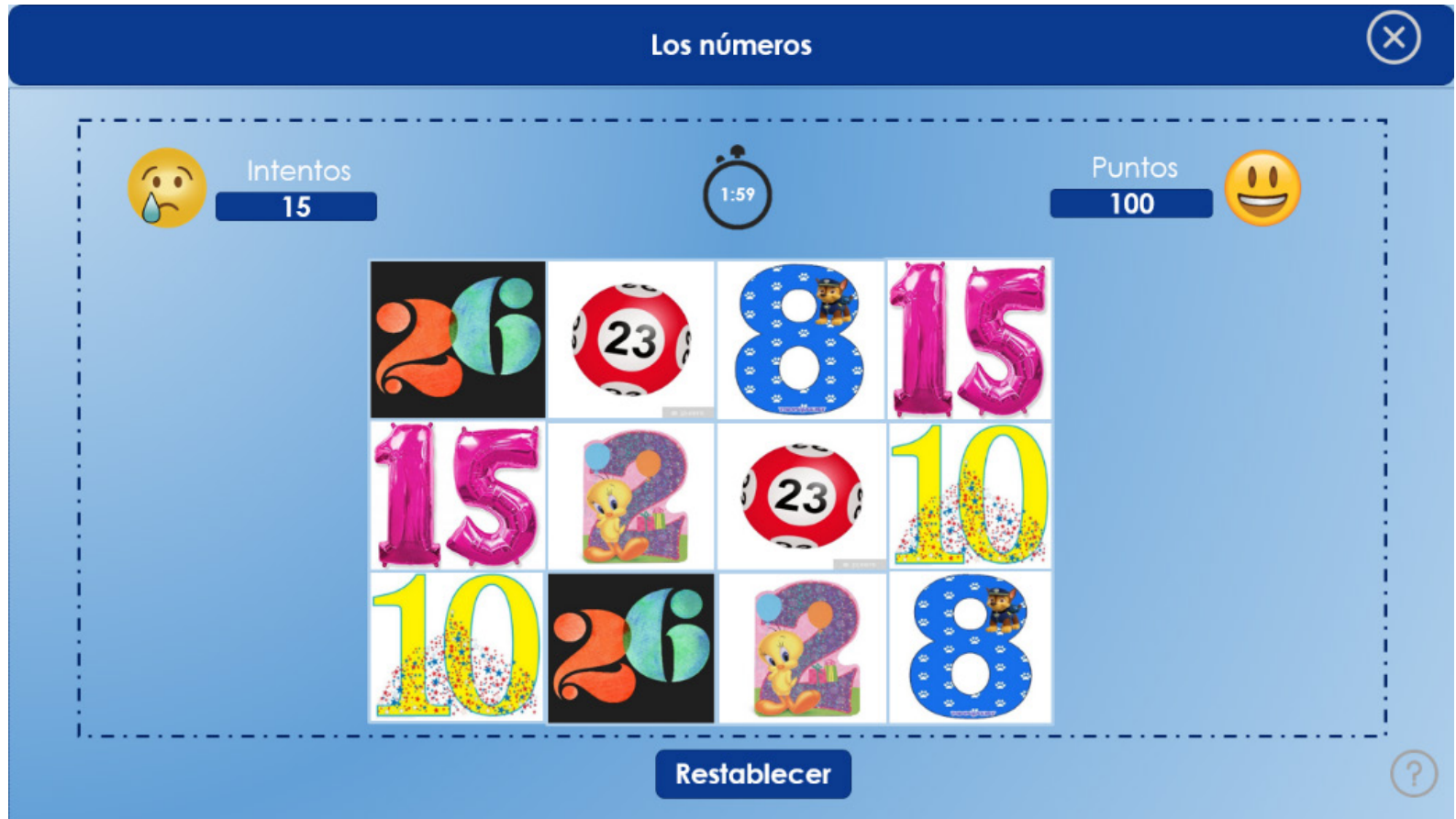

Figure 10. Example of a classic memory game with images of numbers

Figure 10 shows a screenshot with a game finished by a student, where the student completed it in 15 attempts and accumulated 100 points. Pairs are composed by the same image because this was a classic memory game.
A result screen is shown to the student at the end of the game with the number of attempts, points and time, as it is illustrated in the screenshot of Figure 11. 


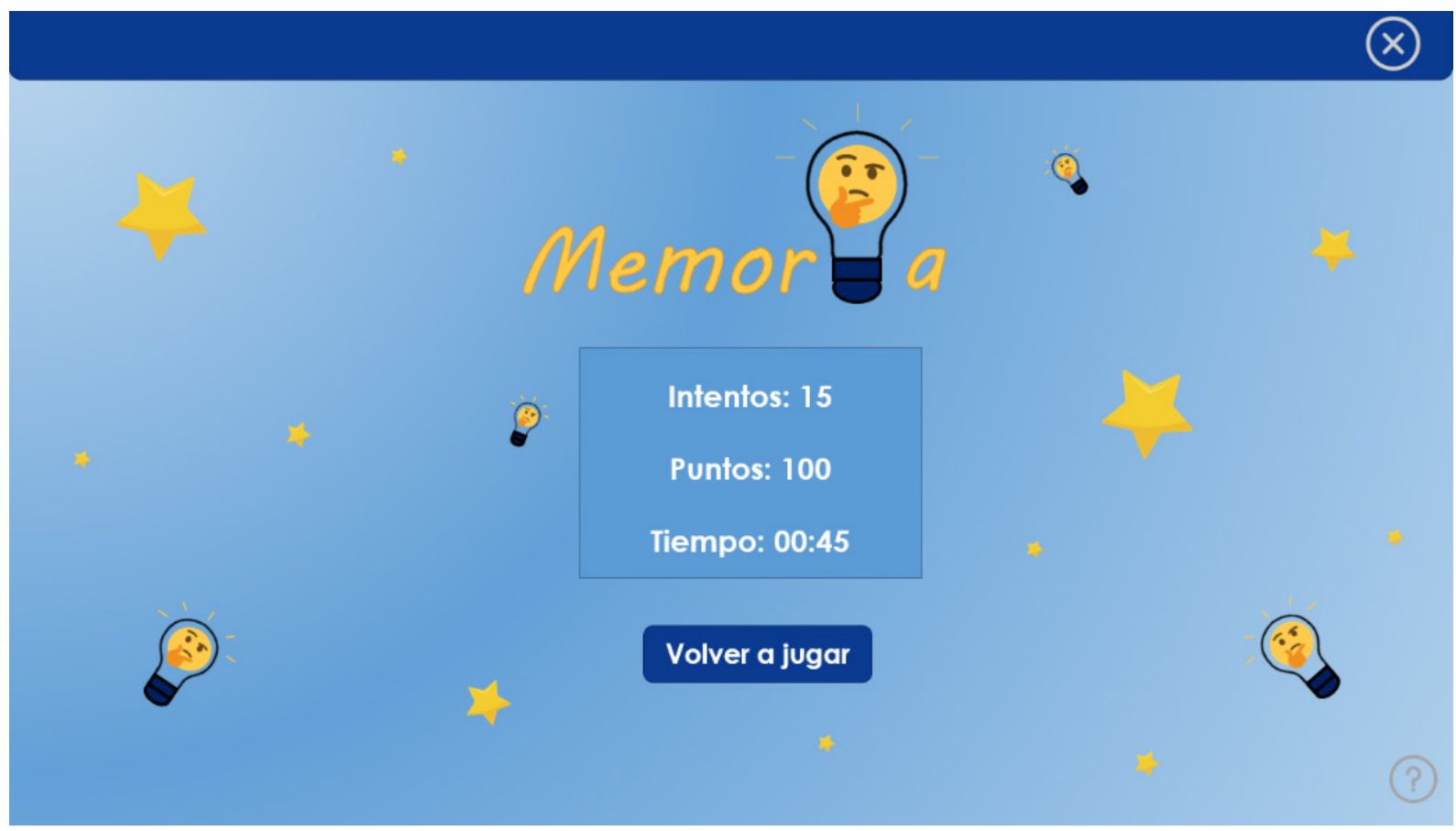

Figure 11. Score, attempts and time in the memory game

\section{Conclusions and Future Work}

This paper presented a web platform to create memory games of four different types: classic memory games, word-image memory games, words memory games, and different images memory games. The aim of the games is to complement the teaching-learning process of different subjects for primary school children. The platform is divided into two systems: the administrator system, which will be used by teachers in order to create memory games; and the games themselves, which are generated by the platform for the students to play. The modules that compose the web platform were described with their functionality, and some of the preliminary interfaces were shown.

It carried out a comparative analysis of five existing tools that contain memory games. The most relevant features were highlighted, such as the possibility to generate new memory games, the cost to play the games, the option to create different types of memory games, the possibility to store the games in the system, the interactivity of the interface, among others. After the comparative analysis, it is important to note that none of the tools evaluated have all of the features reviewed; on the other hand, the web platform presented in this paper fulfilled all of them, which makes it an ideal tool to create memory games of different types.

Further work is needed to complete the development of the web platform in both parts: the memory game generator for teachers, and the visualization of games for students. The web platform will be evaluated by teachers and students in four aspects: functionality, usability, design and didactic features. It is also planned to put the platform on a web server so that teachers and students can use it.

\section{REFERENCES}

[1] H. Salmerón, S. Rodríguez, C. Gutiérrez. Metodologías que optimizan la comunicación en entornos de aprendizaje virtual. Comunicar, Vol. 17, No. 34, 163-171, 2010.

[2] J. Palacios. La cuestión escolar, críticas y alternativas. Barcelona, LAIA, 1978.

[3] M. Meneses, M. Monge. El juego en los niños: enfoque teórico. Educación, Vol. 25, No. 2, 113-124, 2001.

[4] Y. Fernández, M. Ortiz, S. Serra. Importancia del juego para los niños. InforHEM, Vol. 1, No. 1, 38-56, 2015.

[5] B. Montero. Aplicación de juegos didácticos como metodologías de enseñanza: Una Revisión de la Literatura. Pensamiento Matemático, Vol. 7, No. 1, 75-92, 2017.

[6] C. Minerva. El juego: una estrategia importante. Educare, Vol. 6, No. 19, 289-296, 2002.

[7] A. Fantini. Los estilos de aprendizaje en un ambiente mediado por TICs. Herramienta para un mejor rendimiento académico. III Congreso de Tecnología en Educación y Educación en Tecnología. Red de Universidades con Carreras en Informática (RedUNCI), 2008.

[8] S. Ballesteros. Memoria Humana: Investigación y Teoría. Psicothema, Vol. 11, No. 4, 705-723, 1999.

[9] P. Cruz. Utilizar memoramas digitales para el desarrollo de la lógica matemática en niños y niñas de 4 años de edad. 
Tesis de Licenciatura. Tecnológico Superior, Logroño, Ecuador, 2018.

[10] L. Martínea, E. Rincón, A. Domínguez. El juego y el aprendizaje cooperativo en la enseñanza de las ecuaciones de primer grado. 2010 .

[11] M. Nilsen, M. Lundin, C. Wallerstedt, N. Pramling. Evolving and re-mediated activities when preschool children play analogue and digital memory games, Early Years, 2018. DOI: $10.1080 / 09575146.2018 .1460803$

[12] G. Ramani, E. Daubert, G. Lin, S. Kamarsu, A. Wodzinski, S. Jaeggi. Racing dragons and remembering aliens: Benefits of playing number and working memory games on kindergartners' numerical knowledge, 2019. DOI: $10.1111 /$ desc. 12908

[13] M. Selvi, A. Çoşan. The Effect of Using Educational Games in Teaching Kingdoms of Living Things, Universal Journal of Educational Research, Vol. 6 (9), pp. 2019-2028, 2018 DOI: 10.13189/ujer.2018.060921

[14] V. Chi-Pech, L. Narváez, J. López. Software educativo desarrollado para apoyar a niños de educación básica. Tesis de licenciatura. Universidad Autónoma de Yucatán. Tizimín, Yucatán, 2014.

[15] Gynzy. Crea Tu Propio Juego de Memoria: Nueva York. Online available from https://account.gynzy.com/en/es/\#!/it ems/lenguaje/memoria-palabras/32/2169

[16] Azerion. Memoria. Europa: Hello kids. Online available from

http://es.hellokids.com/buscar?recherche=memoria\&search $\mathrm{go}=$

[17] Zinkia Entertainment. Juegos de memoria y retentiva. España: Pocoyo. Online available fromhttps://www.pocoyo .com/juegos-ninos/memoria

[18] Árbol ABC. Juegos de memoria para niños. Online available from https://arbolabc.com/juegos-de-memoria

[19] LucaGames. Memoria. LucaGames. España. Online available from https://www.lucagames.com/memoria

[20] El bosque de las Fantasías. Juegos de memoria para niños de primaria. Juegos Infantiles. Online available from https://juegosinfantiles.bosquedefantasias.com/memoria-nin os

[21] Grupo Promedia. España: Pictojuegos. Online available from: https://www.pictojuegos.com/memory/

[22] Ravensburger. Juegos de memoria online y gratis. Alemania: Memo-juegos. Online available from http://www.memo-jue gos.com/

[23] Juegos de memoria gratis. Juegos de memoria para adultos. Online available from https://www.juegosdememoriagratis. com

[24] Juegos infantiles Pum. Juegos para niños pequeños. Juegos Infantiles Pum. Online available from https://www.juegosin fantilespum.com/index.php 